\title{
Akdeniz ve Arizona Servisi Fidanlarının Morfolojik Kalite Özellikleri
}

\author{
Sezgin AYAN ${ }^{1 *}$, Emre CIVEK ${ }^{2}$, Esra Nurten YER ÇELİK ${ }^{1}$, Orhan GÜLSEVEN ${ }^{3}$, Şeyma Selin \\ AKIN $^{3}$, Ergin YILMAZ ${ }^{3}$
}

${ }^{1}$ Kastamonu Üniversitesi, Orman Fakültesi, Silvikültür ABD, 37100, KASTAMONU

${ }^{2}$ Bursa Orman Bölge Müdürlüğ̈̈, Bursa Orman Fidanlık Müdürlüğ̈̈, 16000, BURSA

${ }^{3}$ Kastamonu Üniversitesi, Fen Bilimleri Enstitüsü, Sürdürülebilir Ormanc1lık, 37100, KASTAMONU

\section{Öz}

Değişen iklim koşulları etkisiyle özellikle Akdeniz havzasında artan yangın riskine karşı servilerin önemi gittikçe artmaktadır. Bu çalışma, farklı yaşlardaki çıplak köklü ve tüplü Akdeniz piramidal servisi (Cupressus sempervirens L. var. pyramidalis (O. Targ. Tozz.) Nyman) ve Arizona servisi (Cupressus arizonica Greene) fidanlarının morfolojik kalite özelliklerinin belirlenmesi amacıyla Samsun-Gelemen Orman Fidanlığında yürütülmüştür. Çalışmada Samsun orijinli 1+0 yaşlı çıplak köklü, $1+1$ ve $1+2$ yaşlı repikajlı-polietilen tüplü fidanlar kullanılmıştır. Fidanlarda morfolojik özellik bakımından; Kök boğazı çapı (KBC), fidan boyu (FB), terminal sürgün boyu (TSB), kök taze ağırlığı (KTA), gövde taze ağırlığı (GTA), kök kuru ağırlığı (KKA), gövde kuru ağırllğı (GKA), fidan kuru ağırlığı (FKA), gürbüzlük indisi (Gi), kuru kök yüzdesi (\%KKök), katlllık indisi (KI) ve Dickson kalite indeksi (DKI) kriterleri baz alınmıştır. Tespit edilen morfolojik özelliklere göre fidanlar, Türk Standartları Enstitüsü (TSE) kriterleri ve Aphalo ve Rikala (2003) GI değerine göre değerlendirilmiștir. Elde edilen sonuçlara göre; her iki türde boy gelişimi ve gövde ağırlı̆̆ında yüksek değerlere sahip fidanlar yetiştirilmesine rağmen, KKA $(0,27-5,43$ gr), \%Kkök (\%15,75-30) ve Ki (2,67-7,25) gibi kök gelişimini temsil eden kriterler bakımından oldukça düşük değerlere sahip olduğu tespit edilmiştir. Fidanlık ekolojisi ve kültürel uygulamalar etkisiyle fidanların kök gelișiminde zayıf davranmaları kurak ve yarı kurak bölgeler için tercih edilmeyecek bir fidan standardını oluşturmuştur. Çalışmada öne çıkan kök gelişimi zayıflığına karşı; su stresi ile şartlandırma, fidan gelişim dönemlerini esas alan kök kesim zamanı ve tekrarı, gübreleme ve sulama rejimi gibi kültürel işlemlerin doğru ve etkin bir şekilde yapılması şiddetle önerilmektedir.

Anahtar Kelimeler: Cupressus, fidan morfolojisi, kalite sınıfları, TSE.

\section{Morphological Quality Characteristics of Mediterranean and Arizona Cypresses Seedlings}

\begin{abstract}
Cypresses are getting importance against the increasing risk of fire, especially in the Mediterranean basin, due to changing climatic conditions. This study was carried out in Samsun-Gelemen Forest Nursery in order to determine morphological quality characteristics of bare rooted and containerised Mediterranean cypres (Cupressus sempervirens L. var. pyramidalis (O. Targ. Tozz.) Nyman) and Arizona cypres (Cupressus arizonica Greene) seedlings of different ages. In the study, 1+0 aged bare rooted, $1+1$ and $1+2$ aged transplanted-polyethylene containerised seedlings from originated Samsun were used. Root collar diameter (KBC), seedling height (FB), the lenght of terminal shoot (TSB), root fresh weight (KTA), stem fresh weight (GTA), root dry weight (KKA), stem dry weight (GKA), seedling dry weight (FKA), sturdiness index (GI), dry root percentage (Kkok\%), the ratio of stem and root dry weight (KI) and Dickson Quality Index (DKI) were utilized as morphological characteristics in the seedlings. The seedlings identified in terms of the morphological characteristics were evaluated according to criteria of Turkish Standart Institute (TSI) and the GI values of Aphalo and Rikala (2003). According to the obtained results for both of the species, although seedlings with high values in terms of height growth and stem weight were grown, very low values were determined in terms of criteria representing root development such as KKA (0,27-5,43 gr), Kkok\% (15,75-30\%) and KI $(2,67-7,25)$. Due to the influence of nursery ecology and cultural practices, the weak growth of the seedlings in root development has formed the traits of the seedlings that will not be preferred for arid and semi-arid regions. Against the weakness of root growth featured in the study; it is strongly suggested that cultural processes such as water stress conditioning, root cutting time and repetition based on seedling development periods, fertilization and irrigation regime be performed correctly and effectively.
\end{abstract}

Keywords: Cypres, seedling morphology, quality standards, TSI.

\section{*Sorumlu Yazar (Corresponding Author):}

Sezgin AYAN (Dr.); Kastamonu Üniversitesi, Orman Fakültesi, Orman Mühendisliği

Bölümü, Kuzeykent Kampüsü, 37000, Kastamonu-Türkiye. Tel: +90 (366) 2801733

E-mail: sezginayan@gmail.com ORCID: 0000-0001-8077-0512
Geliş (Received) : :23.03.2020

Kabul (Accepted) : 04.05.2020

Basım (Published) : 15.08.2020 


\section{Giriş}

Akdeniz servisi (Cupressus sempervirens L.) Doğu Akdeniz bölgesine özgü ve Akdeniz iklimine iyi intibak olmuş bir türdür (Stankova vd., 1996; Baldi vd., 2011). Yüksek kuraklık direnci (Giovanelli ve de Carlo, 2007) ile karakterize edilen tür; kalkerli, killi, kayalık, kuru ve zayıf topraklar gibi ekstrem koşulları da tolere edebilmektedir (Xenopoulos vd., 1990; Gallis vd., 2007). Akdeniz’in her iki tarafındaki; Ürdün, Lübnan, Libya, Girit, Türkiye, Suriye ve İran (Zohary, 1973; Browicz ve Zielinski, 1982) gibi ülkelerin farklı biyoiklim bölgelerinde hem doğal olarak kalıntı popülasyonlar halinde hem de yaygın bir şekilde kültüre edilmektedir (Brofas vd., 2006; Giovanelli ve De Carlo 2007). Suriye'deki ağaçlandırmalar üzerinde yapılan bir araştırmada, Akdeniz servisinin doğal popülasyonlarına kıyasla daha düşük genetik varyasyona sahip olduğu belirtilmektedir (Al-Hawija vd., 2015). Raddi ve Sümer (1999), Batı Akdeniz bölgesinden örneklenen yedi doğal Akdeniz servisi popülasyonunda yürütülen genetik çeşitliliğin belirlenmesi çalışmasında, toplam genetik varyansın \%7'sinin popülasyonlar arası, \%93'ünün ise popülasyon içi genetik farklılıktan kaynaklandığı belirtmişlerdir. Korol vd. (1997), Akdeniz servisinin doğal olarak yetiştiği Kıbrıs, İstanköy, Sisam ve Türkiye'den örneklenen 22 populasyonun baz alındığı araştırmada ise toplam genetik çeşitliliğin \%15'inin popülasyonlar arasında, \%85'inin ise popülasyon içi aileler arasından kaynaklandığını tespit etmişlerdir. Türkiye için de önemli bir gen kaynağı olan servi türünün, doğal yayılışı genel olarak küçük ve dağınık gruplar ve meşcereler halindedir. Türkiye'de Akdeniz ve Ege bölgelerinde oldukça geniş bir alanda yatay, soğuk kuzey rüzgarlarına kapalı vadilerde deniz seviyesinden başlayarak 1100-1200 m'ye kadar dikey olarak doğal yayılış göstermektedir (Sabuncu ve Çalışkan, 2008). Türkiye'deki toplu ve en geniş yayılışını Köprülü Kanyon Milli Parkı ile Mersin ili Aydıncık ilçesi yakınlarındaki Babadili ve Kızılyar derelerini çevreleyen yamaçlarda yapmaktadır (Özçelik, 2005). Akdeniz servisinin ekolojik isteklerinin azlığı, çok kanaatkar oluşu, odun zararlısı böceklere, termitlere, mantarlara ve yangına karşı oldukça dirençli olması, hızlı büyüyen ve çok çeşitli kullanım yerleri bulunan; nispeten yumuşak ve kolay işlenen, düzgün yüzeyler veren bir tür olması, dayanıklı ve kıymetli bir oduna sahip oluşu ekonomik ve ekolojik değerini ortaya koymaktadır. Bu nedenledir ki Batı ve Güney Anadolu'da yapılacak ağaçlandırmalarda, kızılçamdan sonra üzerinde önemle durulması gereken bir tür olduğu belirtmektedir (Özçelik, 2005).

Türkiye için egzotik bir tür olan ve Kuzey Amerika kökenli Arizona servisi (Cupresus arizonica Grene.) ise Meksika ve Batı Arizona dağlarında 2000 m’ye kadar çıkmaktadır. Doğal yayılış sahasında dağınık ve küçük gruplar halinde bulunur. Ekstrem iklim şartlarına diğer servi türlerinden daha çok dayanır. Bilhassa soğuğa karşı Akdeniz servisine oranla daha dayanıklıdır. Tınlı, kumlu, asidik, alkali ve iyi drene olan topraklarda yetişebilir. İtalya'da ve Makedonya'da en kurak mıntıkaların ağaçlandırılmasında bu tür tercih edilmektedir (Gilman ve Watson, 1993; Kolevska vd., 2015). Rüzgar perdesi amaçlı olarak da kullanılan Arizona servisi, Türkiye’ye esas olarak süs bitkisi gayesiyle ithal çalışmalar kapsamında; Marmara, Ege, Akdeniz ve İç Anadolu bölgelerine çok az sayıda orijin ile hatta bazen tek orijin ile temsil edilerek getirilmiştir (Ayan ve Sıvacıoğlu, 2006). Tunçtaner (1998) Ege bölgesinde yüksek performans gösterdiğini belirtmektedir. Boydak vd. (1995) Batı Karadeniz ve Marmara bölgesindeki hızlı gelişen tür deneme ve plantasyonlarında hiç veya çok az kar zararı gözlendiğini belirtmiştir. Birler (1998) ile Ayan ve Sivacıoğlu (2006) tarafından Ege bölgesinde ümit vadeden türler kapsamında olduğu vurgulanmaktadır.

Gerek Akdeniz servisi gerekse Arizona servisi, yangına hassas alanlardaki ağaçlandırma çalışmalarında, yangın emniyet şeritleri ile yol kenarlarında çok tercih edilmesi yanında, canlı çit, rüzgar perdesi, mezarlık ve yol kenarı ağaçlandırmalarında da yaygın bir şekilde fidanları kullanılmaktadır. Verimsiz ormanların ıslahında yeniden orman vasfı kazandırma çalışmaları ile yeni plantasyon tesislerinde; üretim materyalinin orijini, sahanın dikime hazır hale getirilmesi ve kültür bakımı çalışmaları yanında fidan kalitesi; ağaçlandırmanın biyolojik başarısı ve ekonomik karlılığını artırmada rol oynayan önemli faktörlerdendir (Palacios vd., 2009).

Birçok halk kültüründe kutsal ağaç olarak yer alan servilerin dayanıklı odun özelliklerine sahip olması, hızlı büyümesi (Sabuncu ve Çalışkan, 2008), yangına dayanıklı orman ile rüzgâr perdesi tesisinde kullanılması ayrıca, park-bahçe ağaçlandırma çalışmalarındaki estetik formları sebebiyle tercih edilen servi türleri (Özalp, 1991; Mayer ve Aksoy, 1998; Avşar, 2001), değişen iklim koşulları altında özellikle Akdeniz havzasındaki artan yangın riski potansiyeli sebebiyle gittikçe önem kazanmaktadır.

Fidan kalitesinin tespitine yönelik çalışmalarda son yıllara kadar ă̆ırlıklı olarak morfolojik parametreleri baz alan çalışmalar öne çıkmaktadır (Aslan, 1986; Kızmaz, 1993; Yılmaz, 1995; Eler vd., 1993; Donahue ve Upton, 1996; Bilir, 1997; Üçler vd., 2000; Şevik vd., 2003; Demircioğlu vd., 2004; Avanoğlu vd., 2005; Ayan, 2007; Yer ve Ayan, 2011; Ivetić ve Škorić, 2013; Dilaver vd., 2015; Yılmazer ve Bilir, 2016; Bilir ve Çetinkaya, 2018; Çetinkaya ve Bilir, 2019; Ayan vd., 2020). Ritchie ve Shula (1984) fidan, genetik ve morfolojik açıdan ne kadar iyi olursa olsun fizyolojik özelliklerinin değerlendirilmesinin gerekli olduğunu vurgulamaktadırlar. Bununla birlikte; Türkiye fidanlıklarında yapılan fidan kalitesi araştırmalarında gerek ekonomik gerekse zaman tasarrufu 
dikkate alınarak morfolojik fidan kalitesi tayinine yönelik araştırmalar yürütülmüştür. Türkiye'de bu anlamda, karaçam (Kızmaz, 1993; Ayıntapl1, 1995; Avanoğlu vd., 2005; Deligöz, 2007; Yer ve Ayan, 2011), sarıçam (Demircioğlu vd., 2004), Toros sediri (Eler vd., 1993; Ayıntaplı, 1995; Yer ve Ayan, 2011; Çetinkaya ve Bilir, 2019), doğu kayını (Özpay ve Tosun, 1993; Gülseven vd., 2019) ve doğu ladini (Gezer, 1976; Genç, 1992; Ayan, 2002) gibi orman ağacı türlerinde fidan kalite sınıflandırılması üzerine detaylı birçok çalışma gerçekleştirilmiştir. Ürgenç (1986) kaliteli fidan kullanımının, fidan gelişim başarısını arttırmanın yanında kurak ve yarı kurak arazilerdeki fidan tutma oranını da yükselttiğini vurgulamaktadır.

Bu çalışmada; Samsun-Gelemen orman fidanlığı ekolojisinde yetiştirilen ve çalışmanın materyalini oluşturan Arizona servisi (Cupressus arizonica Greene) ve Akdeniz piramidal servisi (Cupressus sempervirens L. var. pyramidalis (O. Targ. Tozz.) Nyman) fidanlarının morfolojik özellikleri incelenerek, Türk Standartları Enstitüsü kalite kriterleri ve Aphalo ve Rikala (2003) gürbüzlük indisi değerlerine göre kalite sınıflarının değerlendirilmesi amaçlanmıştır.

\section{Materyal ve Metot}

\subsection{Materyal}

Çalışma, 2015-2018 yılları arasında Samsun-Gelemen Orman Fidanlığında yürütülmüştür. Fidanlığın genel özellikleri tablo 1'de verilmiştir. Fidan üretiminde orman fidanlığ içerisindeki ağaçlardan elde edilen tohumlar kullanılmıştır. Araştırma objesi olarak, Samsun orijinli 1+0 yaşlı çıplak köklü, 1+1 ve 1+2 yaşlı tüplü Akdeniz piramidal servisi ve Arizona servisi fidanları kullanılmıştır.

Tablo 1.Samsun-Gelemen orman fidanlı̆̆

\begin{tabular}{|c|c|c|c|}
\hline Özellikler & Değerler & Özellikler & Değerler \\
\hline Enlem & $40^{\circ} 50^{\prime}-41^{\circ} 51^{\prime}$ & Yıllık ortalama sıcaklık $\left({ }^{\circ} \mathrm{C}\right)$ & $+14,7$ \\
\hline Boylam & $37^{\circ} 08^{\prime}-34^{\circ} 25^{\prime}$ & Yıllık maksimum sıcaklık $\left({ }^{\circ} \mathrm{C}\right)$ & $+39,7$ \\
\hline Bakı & Kuzeydoğu & Yıllık minimum sıcaklık $\left({ }^{\circ} \mathrm{C}\right)$ & $-12,5$ \\
\hline Rakım (m) & 5 & Yıllık yağıș (mm) & 741,8 \\
\hline Tekstür & Kumlu killi balçık & Yıllık ortalama bağıl nem (\%) & 74,73 \\
\hline pH & 7,3 & Vejetasyon dönemi & Mart-Kasım \\
\hline Kireç (\% $\left.\mathrm{CaCO}_{3}\right)$ & 3,5 & Toplam Azot (mg/L) & 0,12 \\
\hline Organik madde (\%) & 2,3 & $\mathbf{P}_{2} \mathbf{O}_{5}(\mathrm{ppm})$ & 53,8 \\
\hline
\end{tabular}

\subsection{Metot}

\subsubsection{Fidan Üretimi}

Kozalaklar, Samsun-Gelemen fidanlığındaki servi ağaçlarından Kasım-Aralık aylarında toplanmıştır. Sundurma altında 1-1,5 ay kurutularak çıkarılan tohumlara; kuş ve fare zararına karşılık pomarsol forte ile ilaçlama yapılmıştır. 1+2 yaşlı fidanlar için 2015 yılında, 1+1 yaşlı fidanlar için 2016 yılında ve 1+0 yaşlı fidanlar için 2017 yılında tohum ekimleri gerçekleştirilmiştir. Tohum ekimleri Şubat-Mart aylarında yapılmıştır. Ekim öncesi yastıklarda $15 \mathrm{~cm}$ aralıklarla 7 sıra şeklinde 3-5 mm derinlikteki çizgilerde $\mathrm{m}^{2}$ 'ye 25 gr gelecek şekilde tohumlar ekilmiştir. Çizgilerin üzeri toprak-humus-dere kumu örtü materyali ile kapatılmış ve akabinde $15 \mathrm{dk}$ süreyle yağmurlama şeklinde sulama yapılmıştır. Sicaklı̆̆ın mevsim normallerinin üzerinde olduğu günlerde 10:00 ve 14:00'de 5-10 dk; çimlenmeler gerçekleştikten sonra gün aşırı olarak saat 18:00'de 35-40 dk. sulama yapılmıştır. Üretilen 1+0 yaşlı fidanlar için 2016 ve 2017 yıllarında Ocak-Mart ayları arasında şaşırtma işlemi gerçekleştirilmiştir. İşlem, 2:1:1 oranlarında toprak, humus ve pomza harç materyali ile doldurulan 15x30 cm boyutlarındaki polietilen torbalara yapılmıştır. Repikaj işleminden sonra iki günde bir, bir saat sulama yapılmıştır. Tüplü fidanlara Nisan-Mayıs aylarında \%21 amonyum sülfat gübresi uygulanmış ve Nisan-Eylül ayları arasında 5 defa ot bakımı yapılmıştır.

\subsubsection{Morfolojik ölçümler}

Ekim yastıkları üzerinden tesadüfi ve üç tekrarlı olarak sökülen 30'ar fidan vakit kaybedilmeden laboratuvara götürülmüş ve ölçümleri yapılmıştır. Taze fidanların; fidan boyu (FB) ve kök boğaz çapları (KBÇ) ile daha sonra kök boğazından kesilerek gövde ve kök taze ağırlıkları (GTA, KTA) ve terminal sürgün boyu (TSB) ölçülmüştür. 
Ölçümleri tamamlanan fidanlar etüve alınarak $105^{\circ} \mathrm{C}$ 'de 24 saat bekletilmiş, gövde ve kök kuru ağırlıkları (GKA, KKA, FKA) ölçümleri yapılmıştır. Elde edilen veriler yardımıyla aşağıdaki karakterler hesaplanmıştır:

- $\quad$ Kuru kök \% (\%Kkök) $=[$ KKA(g) / FKA (g) $]$ x 100

- $\quad$ Katlılık indisi (Kİ) = GKA/KKA (Thompson, 1985),

- Dickson kalite indeksi (DKİ) =Fidan kuru ağırlık değerinin, Gürbüzlük indisi ile katlılık değeri toplamına bölünmesi ile elde edilen değerdir. Aşağıda belirtilen formül aracılı̆̆ı ile hesaplanmıştır (Dickson vd., 1960).

$$
\mathrm{DKI}=\frac{\text { Fidan Kuru Ağırlığı }}{(\text { Gürbüzlük İndisi })+(\text { Katlılık indisi })}=\frac{\text { FKA }}{\left(\frac{\mathrm{FB}}{\mathrm{KBÇ}}\right)+\left(\frac{\mathrm{GKA}}{\mathrm{KKA}}\right)}
$$

- $\quad$ Gürbüzlük indisi (Gİ) $=[\mathrm{FB}(\mathrm{mm}) / \mathrm{KBÇ}(\mathrm{mm})]$ (Aphalo ve Rikala, 2003),

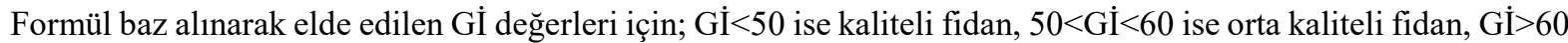
ise düşük kaliteli fidan aralıklarına göre sınıflandırma yapılmıştır (Aphalo ve Rikala, 2003). Ayrıca, fidanların kalite sınıflarının belirlenmesi amacı ile iğne yapraklı türlerin kalite sınıfları kullanılarak TS 2265/Şubat 1988 TSE standartlarına uygunluğu değerlendirilmiştir (Tablo 2).

Tablo 2. TS 2265/Şubat 1988 standartlarına göre Arizona servisi ile Akdeniz servisi fidan kalite sinıflar1 (Anonim, 1988).

\begin{tabular}{|c|c|c|c|}
\hline \multirow{2}{*}{ Fidan Sinıfi } & \multicolumn{3}{|c|}{ Mavi (Arizona servisi) ve Kara Servi (Akdeniz servisi) } \\
\hline & Fidan Boyu (cm) & Kök Boğazı Çapı (mm) & Gövde/Kök \\
\hline & \multicolumn{3}{|c|}{ 1+0 yaşlı } \\
\hline I & $\geq 18.0$ & \multirow{2}{*}{$\geq 2.0$} & $<3$ \\
\hline II & $15.0-17.9$ & & $3-4$ \\
\hline \multirow[t]{2}{*}{ III (Iskarta) } & $<15.0$ & $<2.0$ & $>4$ \\
\hline & \multicolumn{3}{|c|}{ 1+1 yaşlı } \\
\hline $\mathbf{I}$ & $\geq 40.0$ & \multirow{2}{*}{$\geq 2.0$} & $<3$ \\
\hline II & $30.0-39.9$ & & $3-4$ \\
\hline \multirow[t]{2}{*}{ III (Iskarta) } & $<30.0$ & $<2.0$ & $>4$ \\
\hline & \multicolumn{3}{|c|}{$1+2$ yaşlı } \\
\hline I & $\geq 90.0$ & \multirow{2}{*}{$\geq 2.0$} & $<3$ \\
\hline II & $70.0-89.9$ & & $3-4$ \\
\hline III (Iskarta) & $<70$ & $<2.0$ & $>4$ \\
\hline
\end{tabular}

\subsection{3. İstatistiki Değerlendirme}

Fidanlarda ölçülen FB, KBÇ, TSB, GTA, KTA, GKA ve KKA değerleri ile hesaplanan FKA, Gİ, Kİ, \%Kkök ve DKİ değerleri üzerinde temel istatistikler (Aritmetik ortalama, ortalamanın standart hatası, standart sapma, minimum ve maksimum değer ile değişim aralığı) SPSS paket programında belirlenmiştir.

\section{Bulgular ve Tartışma}

Arizona ve Akdeniz servisi fidanlarında yapılmış olan morfolojik ölçümler; FB, KBÇ, TSB, KTA, GTA, KKA, GKA, FKA, Gİ, \%Kkök, Kİ ve DKİ tablo 3 ve 4'de verilmiştir.

Yapılan çalışmalarda, fidan morfolojik özelliklerinden fidan boyu ve kök boğaz çapının, kaliteli fidan yetiştirmede önemli kriterler olduğu bilinmektedir (Dirik, 1993; Long ve Carrier, 1993; McCreary, 1996; South ve Rakestraw, 2002). Tablo 3 incelendiğinde; Arizona servisi fidanlarına ilişkin değerlerden; kuru kök yüzdesi değeri hariç bütün morfolojik özelliklerin beklendiği şekilde fidan yaşı ile paralel bir şekilde arttığı görülmektedir. Akdeniz servisi fidanlarında ise; $1+1$ ve $2+1$ yaşlı polietilen tüplü fidanların KBÇ, TSB ve KTA değerleri hariç, yine yaşa bağlı bir şekilde morfolojik özelliklerde artış yönünde değişim tespit edilmiştir (Tablo 4).

Kolevska vd. (2015) üç farklı tüp tipinde yetiştirdikleri 1 yaşı Arizona servisi fidanlarında sırasıyla ortalama FB 
(17,06-22,37 cm), KBÇ (1,94-2,14 mm), GKA (0,72-1,23 gr), KKA (0,21-0,26 gr), FKA (0,93-1,49 gr), Gİ (8,7910,45), Kİ $(3,43-4,73)$ ve DKİ $(0,08-0,1)$ değerlerini tespit etmişlerdir. Tablo 3'de verilen; $1+0$ çıplak köklü ile 1+1 ve 1+2 yaşlı repikajlı tüplü fidan morfolojik karakterlerinin Kİ hariç tamamının daha uygun olduğu görülmektedir. Yalnızca, 1+0 yaşlı tüplü Arizona fidelerinde Kolevska vd. (2015) tarafindan Kİ 3,43-4,73 olarak saptanmışken, tarafımızca yürütülen bu çalışmada ise Kİ değeri 5,49 ile 6,45 arasında bulunmuştur. Bu durum, Samsun-Gelemen orman fidanlığında fidan gövde gelişimini aşırı bir şekilde tetikleyen uygulama veya uygulamalar olduğunu teyit etmektedir. Parlak vd. (2018)'nın, Bursa orman fidanlığı koşullarında yürüttükleri, biyogübre doz ve çeşitlerinin $1+0$ yaşlı çıplak köklü Arizona servisi fidanlarının boy ve kök boğazı çapı gelişimine etkisini araştırdıkları çalışmalarında; FB değerlerinin $48 \mathrm{~cm}$ ile 55,7 cm, KBÇ değerlerinin ise 6,81 $\mathrm{mm}$ ile 7,76 mm arasında değiştiğini tespit etmişlerdir. Bu FB ve KBÇ aralıklarının; Tablo 3'de verilen SamsunGelemen orman fidanlığında yetiştirilen 1+0 yaşlı çıplak köklü Arizona servisi fidan değerlerinden yüksek olduğu gözlenmiştir. Bu durum türün yetiştirildiği fidanlık koşullarının fidanın büyüme ve gelişme parametreleri üzerinde etkisini göstermektedir.

Tablo 3. Arizona servisi fidanlarının yaşlara göre morfolojik fidan karakterleri

\begin{tabular}{|c|c|c|c|c|c|c|c|}
\hline $\begin{array}{l}\text { Yaş / } \\
\text { Fidan tipi }\end{array}$ & Morfolojik özellikler & Ortalama & $\begin{array}{l}\text { Standart } \\
\text { hata }\end{array}$ & $\begin{array}{l}\text { Standart } \\
\text { sapma }\end{array}$ & $\begin{array}{l}\text { Minimum } \\
\text { değer }\end{array}$ & $\begin{array}{l}\text { Maksimum } \\
\text { değer }\end{array}$ & $\begin{array}{l}\text { Değișim } \\
\text { aralığı }\end{array}$ \\
\hline \multirow{11}{*}{ 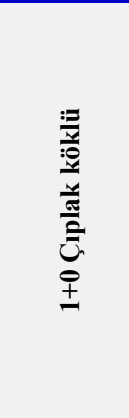 } & Kök boğazı çapı -(KBÇ, mm) & 3,55 & 0,12 & 0,64 & 2,50 & 5,00 & 2,50 \\
\hline & Fidan boyu-(FB, cm) & 38,70 & 0,99 & 5,41 & 30,00 & 50,00 & 20,00 \\
\hline & Kök taze ağırlığı-(KTA, gr) & 0,94 & 0,07 & 0,361 & 0,38 & 1,92 & 1,54 \\
\hline & Gövde taze ağırlığı-(GTA, gr) & 5,33 & 0,39 & 2,17 & 2,17 & 12,25 & 10,08 \\
\hline & Fidan taze ağırlığı-(FTA, gr) & 6,27 & 0,45 & 2,49 & 2,57 & 14,17 & 11,60 \\
\hline & Gövde kuru ağırlığı-(GKA, gr) & 2,04 & 0,15 & 0,82 & 0,68 & 4,49 & 3,81 \\
\hline & Fidan kuru ağırlığı-(FKA, gr) & 2,46 & 0,17 & 0,96 & 0,70 & 5,29 & 4,59 \\
\hline & Gürbüzlük İndisi-(GI) & 110,8 & 3,1 & 16,7 & 75,6 & 143,3 & 67,7 \\
\hline & Kuru kök \%-(\%Kkök) & 0,18 & 0,01 & 0,07 & 0,03 & 0,38 & 0,35 \\
\hline & Katlılık indisi-(KI) & 6,45 & 1,12 & 6,11 & 1,65 & 34,00 & 32,35 \\
\hline & Dickson Kalite İndeksi-(DKİ) & 0,15 & 0,01 & 0,07 & 0,02 & 0,32 & 0,30 \\
\hline \multirow{9}{*}{ 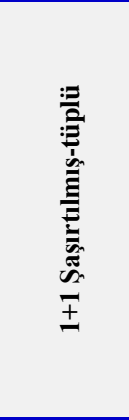 } & Gövde taze ağırlığı-(GTA, gr) & 30,69 & 2,55 & 13,98 & 9,15 & 73,41 & 64,26 \\
\hline & Fidan taze ağırlığı-(FTA, gr) & 36,95 & 3,40 & 18,64 & 10,42 & 105,60 & 95,18 \\
\hline & Kök kuru ağırıı̆̆ı-(KKA, gr) & 2,27 & 0,41 & 2,22 & 0,23 & 12,98 & 12,75 \\
\hline & Gövde kuru ağırlığı-(GKA, gr) & 10,51 & 1,02 & 5,59 & 0,76 & 27,96 & 27,20 \\
\hline & Fidan kuru ağırlığı-(FKA, gr) & 12,78 & 1,36 & 7,46 & 2,62 & 40,94 & 38,32 \\
\hline & Gürbüzlük İndisi-(Gi) & 117,4 & 4,1 & 22,2 & 81,9 & 174,0 & 92,1 \\
\hline & Kuru kök \%-(\%Kkök) & 0,17 & 0,02 & 0,11 & 0,08 & 0,71 & 0,63 \\
\hline & Katlılık indisi-(KI) & 5,82 & 0,43 & 2,36 & 0,41 & 12,00 & 11,59 \\
\hline & Dickson Kalite İndeksi-(DKİ) & 0,80 & 0,12 & 0,63 & 0,12 & 3,58 & 3,46 \\
\hline \multirow{6}{*}{ 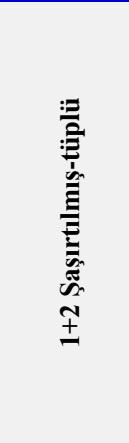 } & Kök boğazı çapı -(KBÇ, mm) & 10,38 & 0,38 & 2,08 & 7,20 & 16,50 & 9,30 \\
\hline & Fidan boyu-(FB, cm) & 144,70 & 3,08 & 16,89 & 102,00 & 184,00 & 82,00 \\
\hline & Gürbüzlük İndisi-(GI) & 143,31 & 4,7 & 25,7 & 98,8 & 188 & 89,2 \\
\hline & Kuru kök \%-(\%Kkök) & 0,16 & 0,01 & 0,05 & 0,10 & 0,37 & 0,27 \\
\hline & Katlılık indisi-(KI) & 5,50 & 0,28 & 1,54 & 1,72 & 8,68 & 6,96 \\
\hline & Dickson Kalite İndeksi-(DKİ) & 1,65 & 0,18 & 0,98 & 0,70 & 5,74 & 5,04 \\
\hline
\end{tabular}

Elde edilen fidan morfolojik özelliklerinde en dikkat çeken husus, gövde/kök ilişkisini temsil eden katlılık indisinin Akdeniz servisi 1+0 yaşlı çıplak köklü fidanları (Ortalama Kİ=2,67) hariç, hem Arizona hem de Akdeniz servisi yaş gruplarında 4,77 ile 7,25 arasında bulunmuş olmasıdır (Tablo 3 ve 4). Genel olarak kurak ekolojik koşullarda kullanılma potansiyeli yüksek olan servilerin, tespit edilen bu Kİ değerlerindeki 1skarta fidanlarının kullanılması mümkün gözükmemektedir. Eyüboğlu (1979), Kİ değerinin bitkinin fizyolojik durumu üzerinde etkili bir kriter olduğunu, ekstrem iklim koşullarında ve kurak alanlarda tutma başarısını arttırmak için bu oranın en fazla 3 olması gerektiğine dikkat çekmiştir. Fidanlarda transpirasyon ile kaybedilen suyun köklerden alınan sudan fazla olması halinde fidanlarda kuraklık ölümlerinin artacağı da belirtilmektedir. 
Tablo 3'te dikkati çeken bir müspet husus ise çıplak köklü fidanlar ile tüpe şaşırtılmış servi fidanları arasındaki Dickson kalite indisi değerleri arasındaki büyük farklardır. Tüpe şaşırtma işlemi, çıplak köklü Arizona servisi fidanlarının DKİ değerini 0,15 'den 1+1 yaşlı tüplü fidanlarda 0,80'e, 2+1 yaşlı tüplü fídanlarda ise 1,64 değerine kadar ulaştırmıştır. Benzer durum, Akdeniz servisi fidanları için de söz konusudur. Şaşırtma ve tüpte yetiştirme uygulamasının DKİ değerlerinde sebep olduğu müspet etki, \%Kkök değerleri üzerinde oluşturmadığı tablo 4'de görülmektedir. Deniz seviyesinden 5 m yükseklikteki, 1lıman iklim koşullarına sahip fidanlık ekolojisi ile sulama rejimi ve \%21'lik amonyum sülfat gübresi uygulaması tüplü fidanların gövde gelişimini aşırı bir şekilde tetiklemiştir. Fidanların kök gelişimi konusunda da şartlar gereği tembel davranmaları Kİ ve \%Kkök değerleri üzerinde kurak, yarı kurak bölgeler için tercih edilmeyecek bir fidan standardını oluşturmuştur. Oysa, Akdeniz Bölgesi için su mevcudiyeti, dağılım rejimi ve alınabilirliği hem doğal ormanlarda hem de plantasyonlarda büyümeyi bozan ana sınırlayıcı faktörler olabilmekte (Resco de Dios vd., 2007), kuraklığa dayanıklı türlerin ve fidanların kullanımı bu bakımdan önem arz etmektedir (Villar-Salvador vd., 1999).

Tablo 4. Akdeniz servisi fidanlarının yaşlara göre morfolojik fidan karakterleri.

\begin{tabular}{|c|c|c|c|c|c|c|c|}
\hline $\begin{array}{l}\text { Yaş / } \\
\text { Fidan tipi }\end{array}$ & Morfolojik özellikler & Ortalama & $\begin{array}{l}\text { Standart } \\
\text { hata }\end{array}$ & $\begin{array}{l}\text { Standart } \\
\text { sapma }\end{array}$ & $\begin{array}{l}\text { Minimum } \\
\text { değer }\end{array}$ & $\begin{array}{l}\text { Maksimum } \\
\text { değer }\end{array}$ & $\begin{array}{l}\text { Değişim } \\
\text { aralığı }\end{array}$ \\
\hline \multirow{13}{*}{ 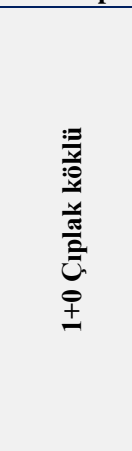 } & Kök boğazı çapı -(KBÇ, mm) & 3,17 & 0,20 & 1,11 & 2,03 & 6,10 & 4,07 \\
\hline & Fidan boyu-(FB, cm) & 22,73 & 0,63 & 3,43 & 17,00 & 34,00 & 17,00 \\
\hline & Son sürgün boyu-(TSB, cm) & 22,73 & 0,63 & 3,43 & 17,00 & 34,00 & 17,00 \\
\hline & Kök taze ağırlığı-(KTA, gr) & 0,46 & 0,04 & 0,20 & 0,14 & 1,00 & 0,86 \\
\hline & Gövde taze ağırlığı-(GTA, gr) & 1,32 & 0,09 & 0,51 & 0,77 & 3,09 & 2,32 \\
\hline & Fidan taze ağırlığı-(FTA, gr) & 1,77 & 0,13 & 0,69 & 0,97 & 4,09 & 3,12 \\
\hline & Kök kuru ağırlığı-(KKA, gr) & 0,27 & 0,03 & 0,15 & 0,07 & 0,69 & 0,62 \\
\hline & Gövde kuru ağırlığı-(GKA, gr) & 0,61 & 0,05 & 0,28 & 0,26 & 1,39 & 1,13 \\
\hline & Fidan kuru ağırlığı-(FKA, gr) & 0,88 & 0,07 & 0,39 & 0,36 & 1,88 & 1,52 \\
\hline & Gürbüzlük İndisi-(Gi) & 76,6 & 3,2 & 17,4 & 44,7 & 108,4 & 63,7 \\
\hline & Kuru kök \%-(\%Kkök) & 0,30 & 0,02 & 0,09 & 0,15 & 0,48 & 0,33 \\
\hline & Katlılık indisi-(KI) & 2,67 & 0,24 & 1,30 & 1,07 & 5,48 & 4,41 \\
\hline & Dickson Kalite İndeksi-(DKİ) & 0,09 & 0,01 & 0,06 & 0,03 & 0,26 & 0,23 \\
\hline \multirow{13}{*}{ 品 } & Kök boğazı çapı -(KBÇ, mm) & 8,35 & 0,24 & 1,33 & 5,80 & 11,30 & 5,50 \\
\hline & Fidan boyu-(FB, cm) & 75,50 & 3,09 & 16,93 & 54,00 & 133,00 & 79,00 \\
\hline & Son sürgün boyu-(TSB, cm) & 49,57 & 2,38 & 13,03 & 34,00 & 95,00 & 61,00 \\
\hline & Kök taze ağırlığı-(KTA, gr) & 5,68 & 0,63 & 3,45 & 2,05 & 18,07 & 16,02 \\
\hline & Gövde taze ağırlığı-(GTA, gr) & 24,13 & 2,48 & 13,61 & 6,19 & 74,08 & 67,89 \\
\hline & Fidan taze ağırlığı-(FTA, gr) & 29,81 & 3,08 & 16,86 & 8,24 & 92,15 & 83,91 \\
\hline & Kök kuru ağırlığı-(KKA, gr) & 2,30 & 0,34 & 1,84 & 0,44 & 8,58 & 8,14 \\
\hline & Gövde kuru ağırlığı-(GKA, gr) & 8,95 & 1,02 & 5,57 & 1,96 & 30,36 & 28,40 \\
\hline & Fidan kuru ağırlığı-(FKA, gr) & 11,25 & 1,30 & 7,12 & 2,40 & 38,94 & 36,54 \\
\hline & Gürbüzlük İndisi-(Gİ) & 90,8 & 2,7 & 15,1 & 61,5 & 124,7 & 63,2 \\
\hline & Kuru kök \%-(\%Kkök) & 0,20 & 0,01 & 0,071 & 0,05 & 0,47 & 0,42 \\
\hline & Katlılık indisi-(KI) & 4,77 & 0,54 & 2,98 & 1,15 & 18,23 & 17,08 \\
\hline & Dickson Kalite İndeksi-(DKİ) & 0,84 & 0,09 & 0,52 & 0,17 & 2,54 & 2,37 \\
\hline \multirow{13}{*}{ :E } & Kök boğazı çapı -(KBÇ, mm) & 6,38 & 0,24 & 1,34 & 4,10 & 9,80 & 5,70 \\
\hline & Fidan boyu-(FB, cm) & 91,10 & 3,02 & 16,55 & 64,00 & 127,00 & 63,00 \\
\hline & Son sürgün boyu-(TSB, cm) & 25,93 & 1,06 & 5,79 & 18,00 & 39,00 & 21,00 \\
\hline & Kök taze ağırlığı-(KTA, gr) & 4,71 & 0,44 & 2,41 & 1,24 & 14,83 & 13,59 \\
\hline & Gövde taze ağırlığı-(GTA, gr) & 29,03 & 2,17 & 11,90 & 10,75 & 72,58 & 61,83 \\
\hline & Fidan taze ağırlığı-(FTA, gr) & 33,74 & 2,58 & 14,10 & 15,08 & 87,41 & 72,33 \\
\hline & Kök kuru ağırlığı-(KKA, gr) & 2,02 & 0,25 & 1,37 & 0,50 & 6,84 & 6,34 \\
\hline & Gövde kuru ağırlığı-(GKA, gr) & 12,31 & 1,08 & 5,90 & 3,18 & 32,30 & 29,12 \\
\hline & Fidan kuru ağırlığı-(FKA, gr) & 14,33 & 1,29 & 7,05 & 4,70 & 39,14 & 34,44 \\
\hline & Gürbüzlük İndisi-(Gİ) & 145,8 & 4,7 & 25,9 & 83,9 & 204,3 & 120,4 \\
\hline & Kuru kök \%-(\%Kkök) & 0,14 & 0,01 & ,06 & 0,06 & 0,32 & 0,26 \\
\hline & Katlılık indisi-(KI) & 7,25 & 0,62 & 3,37 & 2,09 & 15,30 & 13,21 \\
\hline & Dickson Kalite İndeksi-(DKİ) & 0,70 & 0,07 & 0,40 & 0,23 & 2,21 & 1,98 \\
\hline
\end{tabular}

Al-Hawija vd. (2015), Akdeniz servisi üzerine yürüttükleri araştırmada, su stresi ile koşullandırılmış fidanlarda sürgün gelişimi yavaşlarken, kök uzunluğu ve kök biyokütlesinde artışa sebep olduğunu, Suriye'deki 1lık ve sıcak iklim bölgelerindeki orman fidanlıklarda Akdeniz servisi fidanlarının haftada iki kez sulanmasının kök parametreleri performansı için haftada üç kez sulamaya göre daha uygun olabileceğini belirtmişlerdir. Ayrıca, Türkiye fidanlıklarında her fidanlık ekolojisinde ve neredeyse birçok tür için alışılagelmiş uygulamaların hiçbir irdeleme yapılmadan aynı şekilde uygulanması (aynı harç ve tüp boyutları gibi) bu araştırma kapsamındaki servi fidanlarının KKA, \%Kkök, Kİ gibi kriterlerinin arzu edilemeyen nitelikte olmasıyla sonuçlanmıştır. Bu konuda; Kostopoulou vd. $(2010,2011)$ tüp harcı ve tüp boyutunun özellikle fidanın ilk beş haftalık büyüme evresinde çok önemli olduğunu gerek hayatta kalma gerekse plantasyon başarısını etkilediğini belirtmişlerdir. Topic vd. (2009) 
ise Servi fidelerinin sadece farklı değil aynı kap tipinde de farklı geliştiğini, ekimden dört ay sonra yapılan kök sisteminin ilk analizlerinde bütün tüp tiplerinde servi fidelerinin, özellikle daha az gelişmiş olanların, çok zayıf kök büyümesi gösterdiğini belirtmişlerdir.

Tablo 5 incelendiğinde; TSE standartlarına göre Arizona servisi fidanlarının her üç yaş grubu FB ve KBÇ kriterleri bakımından ayrıca, Aphalo ve Rikala (2003)'e göre Gİ kriteri bakımından \%100'ü “1skarta fidan” kategorisinde yer almıştır. Ancak, Kİ değerleri bakımından 1+0 yaşlı çıplak köklü fidanların \%66,67'si, 1+1 ve 2+1 yaşlı tüplü fidanların \%86,6'sı 1skarta fidan niteliğindedir. TSE standartlarındaki FB, KBÇ ve Kİ kriterlerinin üçü birlikte değerlendirildiğinde; 1+0 yaşlı çıplak köklü fidanların \%66,7'si, 1+1 ve 1+2 yaşlı repikajlı-tüplü fidanların ise \%86,7'si ıskarta fidan sınıfında yer almıştır.

Tablo 5. Arizona servi fidanlarında kalite kriterleri, sınıfları ve yüzdeleri.

\begin{tabular}{|c|c|c|c|c|c|c|}
\hline \multirow{3}{*}{ Yaş } & \multirow{3}{*}{ Kalite Sınıfi } & \multicolumn{5}{|c|}{ Arizona servisi } \\
\hline & & \multicolumn{4}{|c|}{ TSE'ye göre } & \multirow{2}{*}{$\begin{array}{c}\text { Gं́ } \\
\text { Aphalo ve Rikala (2003)’ya } \\
\text { göre } \\
\text { Adet } / \%\end{array}$} \\
\hline & & $\begin{array}{c}\text { FB } \\
\text { Adet } / \%\end{array}$ & $\begin{array}{c}\text { KBÇ } \\
\text { Adet } \%\end{array}$ & $\begin{array}{c}\text { KI } \\
\text { Adet } / \%\end{array}$ & $\begin{array}{c}\text { FB-KBÇ-KI } \\
\text { Adet } / \%\end{array}$ & \\
\hline \multirow{3}{*}{$1+0$} & I. Sinıf & $30 / 100$ & $30 / 100$ & $4 / 13,33$ & $4 / 13,3$ & - \\
\hline & II. Sinıf & - & - & $6 / 20$ & $6 / 20$ & - \\
\hline & III Iskarta & - & - & 20/66,67 & $20 / 66,7$ & $30 / 100$ \\
\hline \multirow{3}{*}{$1+1$} & I. Sinıf & $30 / 100$ & $30 / 100$ & $3 / 10$ & $3 / 10$ & \\
\hline & II. Sinıf & - & - & 1/3,33 & $1 / 3,3$ & - \\
\hline & III (Iskarta) & - & - & 26/86,67 & $26 / 86,7$ & $30 / 100$ \\
\hline \multirow{3}{*}{$1+2$} & I. Sinif & $30 / 100$ & $30 / 100$ & $1 / 3,33$ & $1 / 3,3$ & - \\
\hline & II. Sinıf & - & - & $3 / 10$ & $3 / 10$ & - \\
\hline & III (Iskarta) & - & - & $26 / 86,67$ & $26 / 86,7$ & $30 / 100$ \\
\hline
\end{tabular}

Tablo 6'de ise Akdeniz servisi fidanlarının TSE standartlarına göre \%100'ü KBÇ bakımından 1. kalite sınıfında yer almıştır. FB kriteri bakımından 1+0 yaşlı çıplak köklü ve 1+1 yaşlı tüplü fidanların \%100’e yakın oranda 1 . kalite sınıfında iken, 1+2 yaşlı repikajlı tüplü fidanları ise \%53’ü 1. kalite sınıfındadır. Aphalo ve Rikala (2003) Gİ değerlerine göre ise Akdeniz servisi fidanlarının \%100'ü “iskarta fidan” kategorisinde yer almıştır. TSE standartlarındaki FB, KBÇ ve Kİ kriterlerinin üçü birlikte değerlendirildiğinde ise; 1+0 yaşlı çıplak köklü fidanların \%20'si, 1+1 yaşlı repikajl1-tüplü fidanlarının \%53,3’ü ve 1+2 yaşlı repikajlı-tüplü fidanların ise $\% 63,3$ 'ü ıskarta fidan sınıfında yer almıştır.

Tablo 6. Akdeniz servisi fidanlarında kalite kriterleri, sınıfları ve yüzdeleri.

\begin{tabular}{|c|c|c|c|c|c|c|}
\hline \multirow{3}{*}{ Yaş } & \multirow{3}{*}{ Kalite Sınıfı } & \multicolumn{5}{|c|}{ Akdeniz servisi } \\
\hline & & \multicolumn{4}{|c|}{ TSE'ye göre } & \multirow{2}{*}{$\begin{array}{c}\begin{array}{c}\text { Gí } \\
\text { Aphalo ve Rikala (2003)'ya } \\
\text { göre }\end{array} \\
\text { Adet } \%\end{array}$} \\
\hline & & $\begin{array}{c}\text { FB } \\
\text { Adet/\% }\end{array}$ & $\begin{array}{c}\text { KBÇ } \\
\text { Adet/\% }\end{array}$ & $\begin{array}{c}\text { KI } \\
\text { Adet/\% }\end{array}$ & $\begin{array}{c}\text { FB-KBÇ- } \\
\text { KI } \\
\text { Adet } / \% \\
\end{array}$ & \\
\hline \multirow{3}{*}{$1+0$} & I. Sinıf & $29 / 96,6$ & $30 / 100$ & $21 / 70$ & $20 / 66,6$ & - \\
\hline & II. Sinıf & - & - & $4 / 13,3$ & 4/13,3 & - \\
\hline & Iskarta & $1 / 3,3$ & - & $5 / 16,6$ & $6 / 20$ & $30 / 100$ \\
\hline \multirow{3}{*}{$1+1$} & I. Sınıf & $30 / 100$ & $30 / 100$ & $2 / 6,6$ & $2 / 6,6$ & - \\
\hline & II. Sinıf & - & - & $12 / 40$ & $12 / 40$ & - \\
\hline & Iskarta & - & - & $16 / 53,3$ & $16 / 53,3$ & $30 / 100$ \\
\hline \multirow{3}{*}{$1+2$} & I. Sınıf & $16 / 53,3$ & $30 / 100$ & $2 / 6,67$ & $6 / 20$ & - \\
\hline & II. Sinıf & - & - & $1 / 3,3$ & $5 / 16,6$ & - \\
\hline & Iskarta & 14/46,6 & - & $27 / 90$ & 19/63,3 & $30 / 100$ \\
\hline
\end{tabular}


Her iki servi türü ve yaş grupları için FB ve KBÇ kriterleri bakımından TSE standartlarınca büyük oranda 1. sınıf fidan kategorisinde yer almıştır. Bu durum, nem ekonomisi bakımından avantajlı plantasyon sahalarındaki diri örtü problemine karşı boylu fidanların kullanım değeri ve potansiyelini artırabilecektir.

\section{Sonuç ve Öneriler}

Ağaçlandırma alanlarında kullanılan farklı türlere ait fidanlar plantasyon sahasındaki çeşitli stres faktörlerine dayanabilmektedir. Ancak fidanlık ortamı, doğal orman ve ağaçlandırma sahası şartlarından oldukça farklıdır ve daha az çeşitli olması nedeniyle, seleksiyon büyük olasılıkla fidanlıkta doğal habitatlardan çok daha farklı etki yapabilecektir. Bu nedenle ağaçlandırma sahasına ve amaca uygun fidan kullanımı plantasyon başarısını doğrudan etkileyecektir. Bu çalışma sonucunda ifade edilebilecek en önemli ve öz bilgi fidanlık kültürel işlemlerinin fidanlık ekolojisine ve yetiştirilen türe göre çok farklı etkilerinin olabileceğidir. Çalışmada öne çıkan kök gelişimi zayıflığına karşı (düşük KKA, \%Kkök ve Kİ değerleri) su stresi ile şartlandırma, fidanlık ekolojisine özgü fidan gelişim dönemlerini esas alan kök kesim zamanı ve tekrarı, gübreleme ve sulama rejimi gibi kültürel işlemlerin doğru ve etkin bir şekilde yapılması zorunludur. Mevcut katlılık indisi, kök yüzdesi ve kök ağırlığı değerlerine sahip fidanlar, doğal orman ve ağaçlandırma şartlarında değil ancak şehir park-bahçe, mezarlık ve yol boyu ağaçlandırmalarında kullanılabilecek standartlara sahiptir.

\section{Kaynaklar}

1. Al-Hawija, N.B., Lachmuth, S., Welk E., Hensen, I. (2015). Performance of seedlings from natural and afforested populations of Cupressus sempervirens under different temperature and moisture regimes. Plant Species Biology (2015) 30, 257-271.

2. Anonim (1988). TS 2265/Şubat 1988 İğne yapraklı ağaç fidanları standardı, Türk Standartları Enstitüsü, Ankara.

3. Aphalo, P., Rikala, R. (2003). Field performance of silver-birch planting-stock grown at different spacingand in containers of different volume, New Forests 25: 93-108, Kluwer Academic Publishers. Printed in The Netherlands.

4. Aslan, S. (1986). Kazdağı göknarı (A. equitrojani Ascher et Sinten)'nın fidanlık tekniği üzerine çalışmalar. Ormancılık Araştırma Enstitüsü Yayını No; 157,1-42 s.

5. Avanoğlu, B., Ayan, S., Demircioğlu, N., Sivacioğlu, A. (2005). The Evaluation of 2+0-year old Black pine (Pinus nigra Arnold. subsp. pallasiana (Lamb.) Holmboe.) seedlings produced in KastamonuTaşköprü Forest Nursery according to the norms of Turkish Standards Institution, SIGMA: Journal of Engineering and Science, Yıldız Technical University, 2, 73-83, İstanbul.

6. Avşar, M.D. (2001). Kahramanmaraş yöresi park ve bahçelerindeki dallı servilerin (Cupressus sempervirens L. var. horizontalis (Mill.) Gord.) bazı kozalak ve tohum özellikleri. KSU Fen ve Mühendislik Dergisi, 4 (2): 80-87.

7. Ayan, S. (2002). Tüplü Doğu ladini (Picea orientalis (L.) Link.) fidanı yetiştirme ortamları özellikleri ve üretim tekniğinin belirlenmesi, Orm. Bak. Doğu Karadeniz Orm. Arş. Enst. Yayınları, Orm. Bak. Yayın No.179, DKOA Yayın No.14, Teknik Bülten, No:11, Trabzon.

8. Ayan, S. (2007). Containerised seedling propagation, 7th Section (Editors: YAHYAOĞLU, Z. and M. GENÇ, Seedling standardization: Quality seedling propagation and principals of seedling qualification Publication of Süleyman Demirel University, Pub. Nu: 75, p. 301-352, ISBN 978-9944-452-07-6, Isparta.

9. Ayan, S., Gedik, F., Yer Çelik, E.N., Gülseven, O., Yılmaz, E., Akın, Ş.S., Özel, H.B. (2020). Bazı Geniş Yapraklı Orman Ağacı Fidanlarının Morfolojik Özellikleri. Bartın Orman Fakültesi Dergisi, 22 (1) 245255.

10. Ayan, S., Sivacioğlu, A. (2006). Review of the fast growing forest tree species in Turkey, The Bulletin CIDEU, 2: 57-71.

11. Ayıntaplı P. (1995). Serinyol ve Tekir fidanlıklarında üretilen Kızılçam, Anadolu Karaçamı ve Toros Sediri fidanlarında kalite sınıflaması araştırmaları. Yüksek Lisans Tezi, KTÜ Fen Bilimleri Enstitüsü, 116 s. Trabzon.

12. Baldi P., Pedron L., Hietala A. M., La Porta N. (2011). Cold tolerance in cypress (Cupressus sempervirens L.): a physiological and molecular study. Tree Genetics and Genomes 7: 79-90. DOI: 10.1007/s11295-010-0316-8.

13. Bilir, N. (1997). Doğu Karadeniz Bölgesi’nde Toros Sediri (Cedrus libani A. Rich.) Orijin Denemeleri Fidanlık Aşaması. Karadeniz Teknik üniversitesi Fen Bilimleri Enstitüsü. Yüksek Lisans Tezi. 90, Trabzon. 
14. Bilir, N., Çetinkaya, D. (2018). Morphological characteristics in seed orchard and seed stand seedlings of brutian pine (Pinus brutia Ten.). $2^{\text {nd }}$ International Congress on Multidisciplinary, 4-5 May, Cukurova University Adana, p. 57-62.

15. Birler, A.S. (1998). Çevre ve insan: Endüstriyel plantasyonlar (Orman Ağaçları Tarımı): Ed: Kıvanç, M. ve Yücel, E., Anadolu Üniversitesi, Açıköğretim Fakültesi Yayınları. No:1017/560. Bölüm:9, s.174-189, Eskişehir.

16. Boydak, M., Oliver, C.D., Dirik, H. (1995). Introduction possibilities of some native fast growing coniferous forest tree species of the USA to Turkey. Poplar and Fast Growing Forest Tree Species Research Institute, Misselenous publications, Num. 7, İzmit, Turkey.

17. Brofas G., Karetsos G., Dimopoulos P., Tsagari C. (2006). The natural environment of Cupressus sempervirens in Greece as abasis for its use in the Mediterranean region. Land Degradation and Development 17: 645-659. DOI: 10.1002/ldr.750.

18. Browicz, K., Zielinski J. (1982). Chorology of trees and shrubs in South-West Asia and Adjacent Regions. Warszawa-Poznan, Poland.

19. Çetinkaya, D., Bilir, N. (2019). Toros Sediri’nde (Cedrus libani A. Rich.) fidan tipi x fidan morfolojisi etkileşimi. Mehmet Akif Ersoy Üniversitesi Fen Bilimleri Enstitüsü Dergisi 10(1): 28-33. ISSN Online: 1309-2243, http://dergipark.gov.tr/makufebed, https://doi.org/10.29048/makufebed.510959.

20. Deligöz A. (2007). Anadolu karaçamı (Pinus nigra arn. subsp. pallasiana (Lamb.) Holmboe) fidanlarına ait bazı temel morfolojik ve ekofizyolojik özelliklerin dikim başarısına etkisi. Doktora Tezi, SDÜ Fen Bilimleri Enstitüsü, 295 s. Isparta

21. Demircioğlu, N., Ayan, S., Avanoğlu, B., Sivacioğlu, A. (2004). The Evaluation of 2+0-year old Scotch pine (Pinus sylvestris L.) seedlings produced in Kastamonu-Taşköprü forest nursery according to the norms of Turkish Standards Institution, Journal of Engineering, Faculty of Engineering, Pamukkale University, 2 (10) 243-251, Denizli.

22. Dickson, A., Leaf, A.L., Hosner, J.F. (1960). Quality appraisal of white spruce and white pine seedlings stock in nurseries. Forestry Chronicle, 36(1):10-13.

23. Dilaver, M., Seyedi, N., Bilir, N. (2015). Seedling quality and morphology in seed sources and seedling type of brutian pine (Pinus brutia Ten.). World Journal of Agricultural Research, 3 (2):83-85.

24. Dirik, H. (1993). Kızılçam (Pinus brutia Ten.) da bazı önemli fidan karakteristikleri ile dikim başarısı arasındaki ilişkiler. $\dot{I} . \ddot{U}$. Orm. Fak. Derg. Seri A, 2, 51-75.

25. Donahue, J. K., Upton, J.L. (1996). Geographic variation in leaf, cone and seed morphology of Pinus greggii in navite forests. Forest Ecology and Management, 82(1-3), 145-157.

26. Eler, Ü., Keskin, S., Örtel, E. (1993). Toros sediri (Cedrus libani A. Rich.) Fidanlarında Kalite Sınıflarının Belirlenmesi Üzerine Araştırmalar. Ormancılık Araştırma Enstitüsü Dergisi, 240:81-105.

27. Eyüboğlu, A.K. (1979). Fidan. Ormancılık Araştırma Enstitüsü Dergisi, 50, 31-69s,

28. Gallis A.T., Doulis A.G., Papageorgiou A.C. (2007). Variability of cortex terpene composition in Cupressus sempervirens L. provenances grown in Crete, Greece. Silvae Genetica 56(6):294-299.

29. Genç, M. (1992). Doğu Ladini (Picea orientalis (L.) Link) Fidanlarına Ait Bazı Morfolojik ve Fizyolojik Özelliklerle Dikim Başarısı Arasındaki İlişkiler, (Doktora Tezi), KTÜ. Fen Bilimleri Enstitüsü.

30. Gezer, A. (1976). Ağaçlandırmalarda kullanılmaya elverişli doğu ladini (Picea orientalis (L.) link.) fidanlarının bazı morfolojik yapılarına göre tespiti ve bunun sonucunda bulunacak elverişli tipteki fidanların fidanlıklarda üretim oranını arttırma üzerine araştırmalar. OAE Teknik Bülten Serisi No: 91, Ankara.

31. Gilman, E.F., Watson D.G. (1993). Cupressus arizonica var. arizonica Arizona Cypress. Fact Sheet ST222 November 1993, US. Forest Service Department of Agriculture.

32. Giovanelli, A., De Carlo, A. (2007). Micropropagation of Mediterranean cypress (Cupressus sempervirens L.). In: Jain S. M. \& Häggman H. (eds). Protocols for Micropropagation of Woody Trees and Fruits. Springer-Verlag, Berlin, pp. 93-105.

33. Gülseven, O., Ayan, S., Özel, H. B., Yer, E.N. (2019). Farklı doğu kayını (Fagus orientalis Lipsky.) populasyonlarına ait fidanların morfolojik ve fizyolojik karakteristikleri. Türkiye Ormancılık Dergisi, 20(3): 180-186. Isparta.

34. Ivetić, V., Škorić, M. (2013). The impact of seeds provenance and nursery provenance method on Austrian pine (Pinus nigra Arn.) seedlings quality. Annals of Forest Research, 56(2), 297-306.

35. Kızmaz, M. (1993). Karaçam Fidanlarının Kalite Sınıflarının Belirlenmesi Üzerine Araştırmalar. Ormancılık Araştırma Enstitüsü Yayınları, Teknik Bülten No: 238-241, 7-36.

36. Kolevska, D.D., Trajkov P., Maletic V., Terziska, M. (2015). Dynamic of growth and quality of Arizona Cypress (Cupressus arizonica Greene) seedlings from three container types. In: Ivetic V., Stankovic D. (eds.) Proceedings: International Conference Reforestation Challenges. 03-06 June 2015, Belgrade, Serbia. Reforesta. pp. 78-87.

37. Korol , L., Kara, N., Ișık, K., Schliller, G. (1997). Genetic differentiation among and within natural and planted Cupressus sempervirens L. Eastem Mediterranean populations. Silvae Genetica 46 (2-3): 151-155. 
38. Kostopoulou, P., Radoglou, K., Dini-Papanastasi, O. (2011). Performance and quality of Cupressus sempervirens L. miniplug seedlings under reduced photoperiod. European Journal of Forest Research 130: 579-588. DOI: 10.1007/s10342-010-0447-3.

39. Kostopoulou, P., Radoglou, K., Dini-Papanastasi, O., Spyroglou, G. (2010). Enhancing planting stock quality of Italian cypress (Cupressus sempervirens L.) by pre-cultivation in mini-plugs. Ecological Engineering 36: 912-919. DOI: 10.1016/j.ecoleng.2010.04.004.

40. Long, A.J., Carrier, B.D. (1993). Effects of Douglas-fir 2+0 seedling morphology on field performance. New Forests, 7(1), 19-32.

41. Mayer, H., Aksoy, H. (1998). Türkiye Ormanları. Orman Bakanlığı Yayın No. 038 58- 60s.

42. McCreary, D.D. (1996). The effects of stock type and radicle pruning on blue oak morphology and field performance. Ann. Sci. For., 53, 641-648.

43. Özalp, G. (1991). Cupressus sempervirens L. 'in Reşadiye Yarımadası'nda yeni bir yayılışı. Review of the Faculty of Forestry University of İstanbul Seri A. 41(1):98-107.

44. Özçelik, R. (2005). Aydıncık yöresi doğal dallı servi (Cupressus sempervirens L. var. horizontalis (Mill.) Gord) Meşcerelerinde homojenlik durumunun ve gövde niteliklerinin değerlendirilmesi. Çevre ve Orman Bakanlığı Yayın No.283, Müdürlük Yayın no. 031, Batı Akdeniz Ormancılık Araştırma Müdürlüğü Dergisi, Say1. 6, 28-41.

45. Özpay Z., Tosun S. (1993). Kayın (Fagus orientalis Lipsky.) fidanlarının kalite sınıflarının belirlenmesi üzerine araştırmalar. O.A.E. Dergisi, 241, 107-137.

46. Palacios, G., Navarro-Cerrillo, R.M., del Campo, A., Toral, M. (2009). Site preparation, stock quality and planting date effect on early establishment of Holm oak (Quercus ilex L.) seedlings. Ecol. Eng. 35, 3846.

47. Parlak, S., Yılmaz, M., Özgün, O. (2018). Biyogübre uygulamasının Cupresus arizonica ve Acer saccharum L. fidanlarının bazı morfolojik özelliklerine etkisi, Ormancılık Araştırma Dergisi, 5 (2) 117122.

48. Raddi, S., Sümer, S. (1999). Genetic diversity in natural Cupressus sempervirens L. population in Turkey. Biochemical Systematics and Ecology. 7:799-814.

49. Resco de Dios, V., Fischer, C., Colinas, C. (2007). Climate change effects on Mediterranean forests and preventive measures. New Forests 33: 29-40. DOI: 10.1007/s11056-006-9011-X.

50. Ritchie, G.A., Shula, R.G. (1984). Seasonal changes of tissue-water relations in shoots and root systems of Douglas-fir seedlings. Forest Science, 30(2): 538-548.

51.Sabuncu, R., Çalışkan, S. (2008). Akdeniz servisinin (Cupressus sempervirens L.) ekolojisi ve silvikültürü, İstanbul Üniversitesi Orman Fakültesi Dergisi, Seri. B, 58 (1) 53-72.

52. South, D.B., Rakestraw, J.L. (2002). A loblolly pine seedling-grade genotype study. Southern J. Applied Forestry, 26, 1-6.

53. Stankova, T.H., Stankov, H., Panetsos, K. (1996). Juvenile growth rate of Cupressus sempervirens L. from western Crete. Proceedings of the Second Balkan Conference on Study, Conservation and Utilisation of Forest Resources, 3-5 June, Sofia, Volume I: 123-127.

54. Şevik, H., Ayan, S., Demircioğlu, N., Sivacioğlu, A. (2003). The evaluation of bare-rooted and broadleaved forest tree seedlings grown in Gölköy forest nursery (province of Kastamonu) according to the norms of Turkish Standards Institution, Journal of Forestry Faculty of Gazi University, 3 (2) 233-245.

55. Thompson, B.E. (1985). Seedling Morphological Evaluation: What You Can Tell by Looking, Evaluating Seedling Quality: Principles, Procedures, and Predictive Ability of Major Tests, Editor: Duryea M.L., Oregon State University, Corvallis, 55-71.

56. Topic, V., Butorac, L., Durdevic, Z., Kekelic, B., Jelic, G. (2009). Effect of container type on growth and development of seedlings of common cypress (Cupresus sempervirens var. pyramidalis Nyman) in nurseries and forest cultures, Sumarski list, 3-4, CXXXIII, 121-134.

57. Tunçtaner, K. (1998). Yabancı tür ithal çalışmaları ve endüstriyel plantasyonlar için tür seçimi. Hızlı Gelişen Türlerle Yapılan Ağaçlandırma Çalışmalarının değerlendirilmesi ve Yapılacak Çalışmalar (Workshop) s.65-71, Ankara.

58. Üçler, A.Ö., Gülcü, S., Bilir, N. (2000). Anadolu Karaçamı ve Kızılçam'da Tohum Kaynağ1-Morfolojik Fidan Kalitesi İlişkileri. Bildiri Özetleri Kitapçı̆̆ı s, 39. II. Ulusal Fidancılık Sempozyumu, 25-29 Eylül, İzmir.

59. Ürgenç, S. (1986). A ğaçlandırma tekniği. İÜ Orman Fakültesi Yayını, Üniversite Yayın No: 3314, Fakülte Yayın No: 375, 525s. İstanbul.

60. Villar-Salvador, P., Ocaña, L., Peñuelas, J.L., Carrasco, I. (1999). Effects ofwater stress conditioning on thewater relations, root growth capacity, and the nitrogen an non-structural carbohydrate concentration of Pinus halepensis Mill. (Aleppo pine) seedlings. Annals of Forest Science 56: 459-465. DOI: 10.1051/forest: 19990602. 
61. Xenopoulos, S., Andréoli, C., Panconesi, A., Pinto Ganhão, J., Tuset J.J. (1990). Importance of cypress. Progress in EEC Research on Cypress Diseases, Commission of the European Communities, Agriculture, Report EUR 12493 EN, Luxembourg, pp. 1-13.

62. Yer, E.N., Ayan, S. (2011). Eskişehir orman fidanlık koşullarında yetiştirilen çıplak köklü toros sediri ve anadolu karaçam fidanlarının gelişim dönemleri, K.Ü. Orman Fakültesi Dergisi, 11 (2):219-227, Kastamonu.

63. Yılmaz, M. (1995). Karaçam fidanlarının kalite sınıflarının belirlenmesi üzerine araştırmalar, Ormancılık Araştırma Enstitüsü Yayınları, Teknik Bülten No; 238-241, 5-37.

64. Yılmazer, C., Bilir, N. (2016). Effect of seedling type in morphology and quality of brutian pine (Pinus brutia Ten.) Seedlings. IJSRST, 2(5):237-240.

65. Zohary, M. (1973). Geobotanical Foundations of the Middle East, Vols 1 and 2. Gustav Fischer Verlag and Swets and Zeitlinger, Stuttgart and Amsterdam. 